DOI 10.37882/2500-3682.2020.07.01

\title{
ПСИХОЛОГО-ПЕДАГОГИЧЕСКИЕ ПРОБЛЕМЫ ПРИМЕНЕНИЯ ИНТЕРАКТИВНЫХ ТЕХНОЛОГИЙ В ДИСТАНЦИОННОМ ПРЕПОДАВАНИИ ПСИХОЛОГИЧЕСКИХ ДИСЦИПЛИН СТУДЕНТАМ ПЕДАГОГИЧЕСКОГО ВУЗА
}

\section{PSYCHOLOGY-PEDAGOGICAL \\ PROBLEMS OF USING INTERACTIVE TECHNOLOGIES IN DISTANCE TEACHING OF PSYCHOLOGICAL DISCIPLINES TO STUDENTS OF A PEDAGOGICAL UNIVERSITY}

M. Akopova

D. Fursova

Summary: The article presents a theoretical analysis of the problem of organizing «mass» distance education, and considers the possibilities of using interactive teaching methods. The paper considers the features of interaction between teachers and students in the system of distance education. The article defines the main difficulties in conducting online lectures and the specifics of remote work in the organization of active «cloud» practical classes. The authors offer an analysis of their experience in using interactive technologies in conducting distance learning sessions in psychological disciplines.

Keywords: distance education, interactive teaching methods, online lectures, seminar, psychological disciplines.

\section{Акопова Милена Аванесовна}

K.nсх.н., дочент, филиал ГБОУ ВО «Ставропольский государственный педагогический институт» в г. Буденновске milena-ako@mail.ru

Фурсова Диляра Викторовна К.nсх.н., дочент, филиал ГБОУ ВО «Ставропольский государственный педагогический институт» в г. Буденновске dilyarafursova@mail.ru

Аннотация: В статье представлен теоретический анализ проблемы организации «массового» дистанционного образования, рассмотрены возможности использования интерактивных методов обучения. В работе рассмотрены особенности взаимодействия преподавателей и студентов в системе дистанционного образования; определены основные трудности при проведении онлайн-лекций; специфика удаленной работы при организации активных «облачных» практических занятий. Авторы предлагают (на основе имеющегося опыта) некоторые варианты применения интерактивных технологий при проведении дистанционных учебных занятий по психологическим дисциплинам.

Ключевые слова: дистанционное образование, интерактивные методы обучения, онлайн-лекции, практические занятия, психологические дисциплины.
$\Pi$ роблемы дистанционного образования стали разрабатываться в России в конце 90-х гг. XX века, что связано с проведением эксперимента в области дистанционного образования, регулируемого Министерством образования России. К концу нулевых годов технологии дистанционного образования были внедрены всеми крупными вузами страны, что было связано в первую очередь с повышенным спросом населения, желающего получить образование, но не имеющего возможности сделать это в других формах. В целом за последнее десятилетие интерес к дистанционному образованию обусловил активное внедрение его элементов (например, в виде дистанционной поддержки обучения) подавляющим большинством вузов, оставаясь, все же на вторых ролях по сравнению с очным обучением [1].

Однако в связи с известными событиями, приведшим к обязательной самоизоляции граждан все учебные заведения (реализующих, как высшее, так и среднее профессиональное образование) вынуждены были перейти на дистанционный режим обучения, что привело к целому ряду проблем (например, моральной неготовности преподавателей, особенно старшего поколения, к проведению занятий в онлайн-формате или невозможности проведения в данной форме практических занятий по циклам дисциплин спортивного или творческого характера).

В данной работе мы остановимся на тех проблемах, которые возникали у наших преподавателей при проведении дистанционного обучения по психологическим дисциплинам, а также на тех решениях, которые применялись нами.

Дистанционное обучение - это система взаимодействия субъектов образовательного процесса посредством информационно-образовательной среды, позволяющей обмениваться учебной информацией на расстоянии. Основной целью дистанционного обучения является расширение возможностей для получения об- 
разования студентами и удовлетворение их образовательных потребностей за счет активного использования научного и методического потенциала профессорскопреподавательского состава [2, с. 196]. В нашем учебном заведении дистанционная поддержка учебного процесса осуществляется в электронной информационно-образовательной среде на базе платформы moodle, где на каждый преподаваемый курс представлен лекционной материал, практические и тестовые задания, а также материалы методического характера (по усмотрению преподавателя, ведущего курс). Кроме того нашим студентам обеспечен доступ к основным электронно-библиотечным и справочно-правовым системам. Однако на период самоизоляции для проведения занятий по решению администрации нами были дополнительно использованы облачные технологии для проведения практических занятий (с обязательным учетом выполнения заданий студентами в рейтинг-листах в день проведения контрольных мероприятий), а также мультимедийные средства портала eTutorium для проведения онлайн-лекций (в виде вебинаров). Данная организация обучения позволила предупредить многие трудности удаленного обучения студентов, но определила ряд требований к преподавателям, ведущим занятия в дистанционном режиме.

Психологические дисциплины имеют свою специфику. Являясь гуманитарной наукой, психология включает в себя естественнонаучные знания (например, при изучении дисциплины «Психофизиология»). Получение психологических знаний позволяет студентам с одной стороны лучше понять себя, свои личностные особенности (мотивы, направленность, индивидуально-типологические особенности), с другой стороны преподавателю необходимо сформировать у студентов умение использовать полученные знания для взаимодействия с другими людьми (что приобретает особенную важность при обучении будущих педагогов). Знание психологии может помочь будущему педагогу не только в выстраивании своих межличностных отношениях, но и в будущей профессиональной деятельности как для понимания собственных изменений (например, профессиональных деформаций), так и для лучшего понимания субъектов взаимодействия (например, мотивации или психических состояний учащихся).

При изучении психологических дисциплин студенту (как носителю психики, то есть как объекту психологического изучения) сложно избежать сравнений и проведения аналогий с самим собой. О.В. Лобза, В.О. Короткова, рассматривая инновационные технологии преподавания психологии сравнивают процесс изучения с обучением хирурга, который учится делать операцию самому себе. Данное сравнение является немного утрированным, но стоит отметить важность сопровождения преподавателем изучения психологических дисциплин.
Перед преподавателем стоит задача вызвать интерес, а не сопротивление к психологической науке; раскрыть возможности реализации психологических знаний в выбранной профессиональной деятельности и дать возможность применить полученные знания в процессе обучения [3, с. 116]. Все это требует применения интерактивных методов обучения, что в условиях дистанционного образования несколько затруднено и требует особой организации работы преподавателя и студентов.

Главное в интерактивном обучении - активность студентов (физическая, социальная и познавательная), то есть взаимодействие обучающихся между собой и преподавателем, что позволяет создать условия для взаимообучения и коллективной мыследеятельности [4] Ситуация дистанционного обучения подразумевает существенную физическую и психологическую отдаленность субъектов образовательного процесса друг от друга. Это сказывается на восприятии обучения каждым из его участников, а также на его эффективности в целом. Начнем наш обзор возможностей применения интерактивных технологий с проведения онлайн-лекций.

В психолого-педагогической литературе вы можете найти ряд требований к лекциям, проводимым в любом формате, а именно: научность и информативность; доказательность и аргументированность; наличие ярких примеров и фактов; эмоциональность; постановка вопросов для размышлений; четкая структура и логика изложения; подчеркивание выводов; изложение ясным языком; использование аудиовизуальных материалов [например, 5]. Однако зачастую (по отзывам студентов) преподаватели (даже при очном взаимодействии) нарушают даже эти стандартные требования или пренебрегают отдельными критериями в пользу других (один из частых примеров: показ научно-популярных фильмов на занятиях по психологии, что может, конечно, вызвать эмоциональный отклик у студентов, но вряд ли соответствует ряду других критериев, например, научности).

В ситуации онлайн-лекций у преподавателей возникает больше проблем со стимулированием интереса слушателей, а также отслеживания реакций студентов на излагаемый материал. В ситуации очного общения преподаватели имеют возможность оценить студентов не только в плане имеющихся у них знаний, но и определить личностные особенности студента. В ситуации дистанционного обучения на лекции преподаватель имеет дело не столько с самим студентом, сколько с текстом его сообщения, содержащего в лучшем случае вопрос или уточнение. По сути, преподавать в условиях очного и дистанционного образования значит взаимодействовать с разными объектами (с живыми реакциями студента - при очном обучении, и с собственными проекциями и текстами - при дистанционном) [6]. 
Онлайн-лекция с точки зрения студента также имеет как преимущества (например, отсутствие такого отвлекающего фактора, как аудитория), так и свои недостатки (отсутствие прямого контакт с лектором). Эти особенности многократно резонируются, когда мы говорим о преподавании психологических дисциплин. Получение высшего образования вообще, и педагогической профессии, в частности - это обретение ценностей, формирование определенного мировоззрения. А лекция - это не столько способ передачи фактических знаний (которые в условиях современного информационного общества студент может приобрести не только от преподавателя), но средство формирования общих ценностно-смысловых ориентиров (особенно когда речь идет о психологических дисциплинах). А в условиях дистанционного обучения отсутствует возможность полноценного диспута, в котором и происходит переоценка позиций студента (а иногда и преподавателя).

Дистанционное образование в плане передачи знаний от преподавателя обусловливает ряд рассогласований между ожиданиями студента и реальностью. Так, студент ожидает, что предоставленный ему учебный материал будет понятен, в реальности он, вполне вероятно, получит нечто иное: учебные тексты написано сухо и, быть может, ничего общего не имеют с точкой зрения преподавателя, так как заимствованы из учебников. Вместо «реальной» коммуникации студент получает взаимодействие с «говорящей головой» [6].

С учетом перечисленных особенностей, которые с одной стороны определяют необходимость применения интерактивных технологий, а с другой стороны определяют сложности для применения большинства из них, мы, исходя из результатов нашей работы, можем дать следующие рекомендации по организации активного взаимодействия студентов при проведении онлайн-лекций:

- преподавателю необходимо постоянно поддерживать контакт с аудиторией, поощрять вопросы от слушателей, уточнять, есть ли звук, если возникают помехи, проверять чат на наличие новых сообщений. Эти простые приемы позволяют преподавателю получать обратную связь от слушателей лекции и отслеживать их реакцию на обсуждаемые вопросы;

- в силу изолированности студентов друг от друга, которая вызвана спецификой дистанционного образования, где каждый студент изучает материал самостоятельно в своем собственном режиме можно предложить студентам в период чтения лекции актуализировать имеющиеся у них знания посредством вопросов, небольших тестов, анализа конкретных ситуаций. Кроме того, используя онлайн-лекцию как средство связи со студентами, преподаватель может посвятить несколько минут анализу выполненных практических работ, разбору типичных ошибок, объяснению наиболее важных вопросов, возникающих у студентов при выполнении заданий;

- рекомендуется также использовать при чтении лекции опытов, экспериментов, наглядного материала. Например, при объяснении студентам темы по диагностике эмоционального выгорания (дисциплина «Профилактика профессионального выгорания педагога»), мы предлагаем на слайде студентам одну из картинок теста тематической апперцепции Хеккаузена и просим их подумать и ответить на стандартные вопросы данной методики (что происходит и кто эти люди; как возникла эта ситуация, что произошло перед этим; что думает каждый изображенный на картинке человек, чего каждый из них хочет; что произойдет дальше, чем все закончится) или даже просто поделиться общим впечатлением от изображенного. А затем, получив ответы студентов, акцентируем их внимание на разницу в восприятии одной и той же картинки. Это позволит нам без лишних объяснений дать студентам четкое представление о механизме проекции, о сути самой методики и параллельно показать роль снижения профессиональной мотивации при возникновении эмоционального выгорания;

- предложить студентам вспомнить примеры, демонстрирующие тот или иной процесс из их личного опыта. Например, при объяснении феномена послепроизвольного внимания, можем предложить студентам вспомнить случаи, когда они вначале заставляли себя заниматься какой-либо деятельностью, а затем увлекались ею и отписаться кратко в чате (кто-то вспомнит, как читал «Войну и мир», кто-то как занимался уборкой, кто-то не отпишется, но возьмет на заметку наблюдения своих одногруппников).

При проведении дистанционных практических занятий также можно отметить ряд моментов, препятствующих интерактивному обучению. У самих студентов достаточно часто снижена мотивация выполнения практических работ (прокрастинация, демотивация, непонимание материала, отсроченность в оценивании работы), что также демотивирует преподавателя [7]. Основной трудностью в условиях дистанционного обучения является, то, что в связи с лёгкостью получения информации в Интернете практическое занятие может превратиться из активной в репродуктивную форму обучения. В условиях дистанционного обучения преподаватель должен подготовить для студентов задания, которые заставят его не только изучить предлагаемый лекционный и дополнительный материал и систематизировать его (например, одним из стандартных заданий, показывающих насколько студент усвоил основной материал - соста- 
вить схему или таблицу по теме), не только заставить студентов включить процессы осмысления и практического применения изученного материала, но и позволят преподавателю проверить уровень освоения материала.

Данная проблема, конечно, не является новой и достаточно широко представлена, в том числе в современных научных публикациях. Например, Е.Ю. Гайдученко считает, что в условиях дистанционного образования можно создавать интерактивные материалы и различные маршруты, которые позволят направлять процесс обучения в зависимости от подготовки студента - то есть персонифицировать обучение в рамках одного потока или группы. А именно - предоставлять доступ к группе материалов на основе заданных критериев (по определенным ответам на вопросы, набранным баллам и т. д.) и дифференцировать этот доступ [7, с. 48]. Некоторые авторы высоко оценивают такую активную форму работы как семинар Moodle, где обучающиеся цикла выполняют собственную работу, а также выступают в роли рецензентов, оценивая результаты своих коллег. Итоговая оценка модуля «Семинар» учитывает и качество собственных работ обучающихся, и деятельность обучающихся в роли рецензентов [например, 8].

Опираясь на опыт других педагогов [9; 10] и с учетом специфики применения облачных технологий, нами использовались следующие методы интерактивного обучения для повышения качества проведения дистанционных практических занятий.

Применение метода проектов, который при очной форме обучения чаще используется в организации самостоятельной работы студентов, в условиях дистанционного обучения может помочь преподавателю организовать взаимодействие между разными по успеваемости студентами с конкретным практическим результатом. Например, мы, разбив группу студентов на несколько подгрупп, предлагали им разработать, опираясь на разные подходы (феноменологический, герменевтический, конструктивистский), программу психолого-педагогического исследования (дисциплина «Качественные количественные методы психологических и педагогических исследований») или составить профессиограмму педагогов разных направлений по предлагаемой схеме (дисциплина «Психофизиология профессиональной деятельности») При этом обязательным условием является приложение к проекту скриншотов переписки студентов (она велась как правило в соц.сетях или в мессенджерах). Эта аналитическая работа включает в себя несколько этапов, которые позволяют улучшить навыки логического мышления, максимально раскрывают творческие возможности студентов и стимулируют их к научно-исследовательской работе.

Применение кейс-методов или решение ситуацион- ных задач позволяет стимулировать активность студентов. Мы предлагаем студентам небольшую ситуацию и сопровождающий вопрос. Например, при изучении дисциплины «Инклюзивное образование» студентам предлагается ситуация: «Ученица К. была зачислена в третий класс общеобразовательной школы. После комплексной оценки развития ребенка были определены особые образовательные потребности - трудности в обучении, языковые расстройства. С нею занимался вспомогательный педагогический персонал. В начале она была очень тихой, не общалась ни с кем, боялась толпы, боялась больших и просторных помещений в школе. Постепенно она начала улыбаться, отвечать на приветствия, позже сама первой начала здороваться. В течение нескольких лет учителя, школьный психолог, вспомогательный педагогический персонал много работали с ней. Определите пути помощи учителя и психолога данному ребенку». В условиях дистанционного обучения мы просили студентов вначале предложить свои варианты решения. Затем преподаватель сводил все ответы студентов в один файл и просил студентов оценить по критериям эффективности и оригинальности предлагаемые их одногруппниками варианты решения.

На очных практических занятиях мы часто используем тренинг как метод интерактивного обучения психологическим дисциплинам. Конечно, в условиях дистанционного обучения использование данного метода несколько затруднено, но не невозможно. Так, при изучении дисциплины «Социальная психология» в рамках практических занятий мы предлагали студентам сделать самостоятельно отдельные тренинговые упражнения (например, при изучении темы «Межличностные отношения» студентам предлагалось упражнение «Список претензий», а при изучении темы «Конфликтологическая культура» предлагалось упражнение «Детские конфликты»). Студенты должны были выполнить упражнение, а затем обсудить его с партнером (для выполнения этого задания студенты разбивались на пары). В качестве отчета мы просили представить небольшой рефлексивный анализ своих результатов в сравнении с результатами одногруппника-партнера. Данный метод позволяет выработать у студентов важные навыки взаимодействия и рефлексии.

Таким образом, можно сделать ряд выводов о работе педагога в условиях дистанционного обучения. В этой области существует ряд актуальных проблем, которые необходимо решать для поднятия его качества (проводить исследования в области применения информационных технологий, изучать влияние дистанционного обучения на преподавателей и студентов, находить новые возможности для активизации всех участников образовательного процесса). Однако в целом можно отметить, что каждый преподаватель может наполнить дистанционное образование особым содержанием, которое по- 
зволит развить у студентов все необходимые компетенции. В нашем исследовании дан небольшой обзор опыта применения интерактивных технологий на лекциях и практических занятиях в условиях дистанционного об- учения психологическим дисциплинам, который позволяет заключить, что в любых условиях можно выйти за рамки традиционных форм обучения, опираясь на креативность преподавателя и мотивацию студентов.

\section{ЛИТЕРАТУРА}

1. Пьянников М.М. К вопросу об истории дистанционного образования // Педагогика и психология. 2011. № 5. С. 119- 123.

2. Кульбах 0.С., Заварзнина Н.Ю., Зинкевич Е.Р. Опыт применения технологии дистанционного обучения на факультете клинической психологии // Педагогическое образование в России. 2013. № 6. С. 196 - 200.

3. Лобза 0.В., Короткова В.О. Инновационные технологии преподавания психологии для студентов непрофильных специальностей // Педагогическое образование и наука. 2018. № 2. с. 115- 119.

4. Добрынина Т.Н. Интерактивная форма семинарских занятий в высшей школе // Педагогическое образование и наука. 2009. №8. С. 70 -75

5. Вузовская лекция. / Сост. В.С. Зайцев. Челябинск: Издательство ЗАО «Библиотека А.Миллера», 2018. 43 с.

6. Лифшиц М.В. Особенности межличностной коммуникации студента и преподавателя в ситуации дистанционного обучения // Дистанционные технологии в профессиональном психологическом образовании, психологии и психоанализе. Сборник научных трудов по материалам международной научнопрактической конференции, проведенной в ЧОУВ0 «Восточно-Европейский Институт психоанализа» 19.11.2019 г. / Под ред. проф. М.М. Решетникова. СПб.: ВЕИП, 2020. С. 22-28

7. Гайдученко Е.Ю. Разработка и ведение дистанционного курса: типичные трудности и их преодоление с позиции преподавателя // Дистанционные технологии в профессиональном психологическом образовании, психологии и психоанализе. Сборник научных трудов по материалам международной научно-практической конференции, проведенной в чОУВ0 «Восточно-Европейский Институт психоанализа» 19.11.2019 г. / Под ред. проф. М.М. Решетникова. СПб.: ВЕИП, 2020. С. 46-51

8. Кравченко Г.В., Волженина Н.В. Работа в системе Мoodle: руководство пользователя. Учебное пособие. URL: http://phys.bspu.by/newmoodle/pluginfile. php/806/mod_resource/content/2/Пособие_Moodle.pdf (дата обращения: 17.04.2020).

9. Цыплёнкова И.В. Интерактивное обучение с использованием информационных технологий: интерактивные методы на лекционных и практических занятиях (семинарах) // Электронный научно-методический журнал Омского ГАУ. 2016. Спецвыпуск №2. URL: http://e-journal.omgau.ru/index.php/ spetsvypusk-2/31-spets02/449-00198 (дата обращения: 17.04.2020).

10. Зубов В.Е. Методические вопросы организации и проведения электронных семинаров в дистанционном обучении // Философия образования. 2011. № 6 (39). C. 315-322.

( А Акопова Милена Аванесовна (milena-ako@mail.ru), Фурсова Диляра Викторовна (dilyarafursova@mail.ru).

Журнал «Современная наука: актуальные проблемы теории и практики» 